\title{
Identifying Motivational Styles in Educational Gamification
}

\author{
Jared R. Chapman, Ph.D, MBA, MSc - Utah Valley University - jared.chapman@uvu.edu \\ Peter Rich, Ph.D. - Brigham Young University - peter_rich@byu.edu
}

\begin{abstract}
Little work has been done to understand the motivational impact of specific game elements and how they combine to form student motivational styles in educational gamification. In this exploratory study we evaluate the level of motivation reported for a variety of game elements by 184 students. Using this data we generated a principle components analysis to identify the underlying factor structure that govern students' motivational styles. Four motivational styles were identified: (1) Personal Progress - being motivated by gamified elements that show one's individual progress in a course; (2) Competition and Praise - being motivated by game elements that show one's progress compared to their peers and provide social reinforcing feedback; (3) Individual Assignments - being motivated by completing traditional assignments and exams; and (4) Group Work - being motivated by social assignments like group work and peer review.
\end{abstract}

\section{Introduction}

Over the past few decades, the internet has played an increasing role in education. More and more, courses are moving to distance and hybrid formats giving more students easier access to education. Online classes have been shown to be especially beneficial for business and computer information systems courses [27]. However, internet courses can limit interaction with teachers and classmates and reduce student motivation [34]. Atchley, Wingenbach [3] found that course completion rates were significantly lower for online courses and Jaggars [27] found that low-income and underprepared students have withdrawal rates that are $10-15 \%$ higher in online courses. Regardless of improvements made in content, presentation, and modes of interaction, online learning does not seem to transmit emotion or engage students in the same way that teachers can [37]. Addressing learner motivation will become more and more important as online courses become more prevalent.

In contrast, games have captured human motivation in every society for thousands of years. In modern times, video games have perfected their motivational pull to near addiction. Angry Birds has been downloaded more than 1 billion times and more than 10 million subscribers have spent more than 50 billion hours playing World of War Craft [36]. The average gamer, comprising some $40 \%$ of the population, is now 20-34 years old, nearly half of whom are women [28]. This increase and parity in the gaming population has led to a culture of college students who may be more readily prepared to engage in game-based activities for serious learning. What can we learn from games that might encourage students to spend more time in their studies, be more engaged, and as a result learn more? Seeking answers to these questions is at the core of understanding and applying gamification in education.

Gamification is the use of game elements in nongame contexts. It is used in many environments including customer loyalty, marketing, performance management, and health. Its purpose is to modify participant behavior to achieve specific outcomes. Technology pundits generally believe the use of gamification will continue to grow in the coming decades and most consider this a positive trend [1].

Gamification's success in industry suggests that it could also be used in education to increase student engagement and drive learning behavior [33, 46]. In fact, traditional education already supports many game elements. For example, there are points for assignments; grades and diplomas as badges; rewards and punishments; leveling up from grade to grade; and status indicators [33, 47]. However, there is a stark contrast between the engagement levels afforded by traditional education vs. those achieved in games. While millions of people freely engage in games for recreation [36], schools experience disengagement, cheating, learned helplessness, and dropping out [33]. Reasons for dropping out or low performance include boredom or lack of engagement, absenteeism, and distraction [25]. While traditional education bears characteristics of a game, it is not a very good game [47] from a motivational standpoint. Educational gamification works to improve educational experiences by making game elements more salient 
and transparent to students and engaging them at a social, emotional, and cognitive level. Its goal is to help students want to participate more deeply in their education and perhaps change their self-concept as learners [33]. The purpose of this study is to identify patterns in student motivation afforded by specific game elements.

\section{Theories Guiding Gamification}

\subsection{Definition of Educational Gamification}

While numerous definitions have been proposed for gamification $33,17,39,48$ p. 26, 23, 46, 28, 18, $16,19,26,29$ p. 10,45 p. 75,32$]$, educational gamification has not been specifically defined. Three gamification definitions stand out to us as well articulated and precise:

- Gamification: The use of video game elements in non-gaming systems to improve user experience (UX) and user engagement [19]

- Meaningful gamification: The integration of user-centered game design elements into nongame contexts [5']

- Gamification: the use of game attributes outside the context of a game with the purpose of affecting learning-related behaviors or attitudes [32]

Drawing upon these three definitions, we propose a definition for educational gamification:

- Educational gamification: The use of studentcentered game elements in non-game educational systems to improve student experience; drive engagement with content and learning activities; model and teach effective learner skills; and enhance student attitude and identity as a learner.

This definition acknowledges the unique interests of educational gamification and places it within the larger context of learning principles. It also emphasizes the importance of placing the learning experience in the context of learner's needs and interests. While we recognize that this definition merits further explanation, doing so is beyond the scope of this paper and will require a future essay to adequately describe it.

\subsection{Educational Gamification vs. Educational Games}

The term gamification is sometimes mistakenly applied to all learning games. However, Deterding, Dixon, et al. [46] suggest that gamification is a unique domain, distinct from serious games, playful design, gamefulness, and gameful interaction. Gamification is the use of game elements in non-game contexts. It affords gameful interpretation and action without including all of the elements of a proper game [46]. Many of the ideas underlying gamification have been explored for decades in the human computer interaction field [18]. However, the study of gamification as a specific domain is young. The term gamification was first used in 2008 but was not common until the last half of 2010.

Creating a traditional learning game can be a very involved experience requiring significant time and costly resources to produce. These types of learning games are often tightly integrated with the content and cannot easily be repurposed. In contrast, a welldesigned educational gamification framework can be applied to a variety of existing courses fairly quickly with minimal time and resources. Where a learning game may involve a detailed narrative and extensive graphics and other media assets, basic educational gamification might mean simply injecting isolated game elements, like a leader board, a course map, or an experience points meter, into an existing learning environment [21]. Of course, capitalizing on more of the benefits and opportunities afforded by gamification would likely require further massaging course content and tweaking how students interact with the course. Yet the overall design of experiences and commitment of resources would likely be much different that when designing a learning game.

\subsection{Self-determination Theory}

Deterding [15] suggests that Self-determination Theory (SDT) is an appropriated theoretical foundation for gamification. SDT assumes that humans have innate tendencies towards psychological growth; a unified self; well-being; and autonomous, responsible behavior. According to the theory, these tendencies are best realized when the social environment supports three basic needs: competence, relatedness, and autonomy. Competence is feeling effective in one's social environment; relatedness is feeling connected to others; and autonomy is being the perceived cause of one's own behavior. It is important to note that SDT's concept of autonomy is not necessarily insulated from external influences. It allows for influences from the environment as long as the person has endorsed and internalized those influences. This allows for a more nuanced explanation of both extrinsic and intrinsic motivation, as described below [25]. SDT includes two subtheories relevant to gamification: Cognitive Evaluation Theory and Organismic Integration Theory, described below. 


\subsection{Cognitive Evaluation Theory}

Cognitive Evaluation Theory (CET) primarily addresses intrinsic motivation, i.e., freely participating in an activity because of interest, enjoyment, optimal challenge, and satisfaction derived inherently from the activity. According to CET, intrinsic motivation increases as competence and autonomy needs are more fully met. External influences, like rewards and positive feedback, can either increase or limit intrinsic motivation depending on whether or not they impair or support perceptions of competence and autonomy. In other words, the impact of an external influence on intrinsic motivation depends on whether or not it is seen as controlling vs. informational, and whether it enhances vs. limits perceptions of competence and autonomy [25]. For example, numerous empirical studies and meta-analyses show that tangible and expected rewards reduce intrinsic motivation, however, verbal rewards or praise can enhance intrinsic motivation $[15,12,13]$.

\subsection{Organismic Integration Theory}

Organismic Integration Theory (OIT) primarily addresses extrinsic motivation, i.e., participation in an uninteresting activity. OIT assumes that people naturally internalize extrinsic activities, making our response to them more like our response to intrinsic motivation, if conditions are supportive. Thus, uninteresting activities can shift along a spectrum from external regulation, with external controlling influences, to integrated regulation, with selfcontrolling behavior [25, 43]. For example, when forced to do something by an authority figure, a person might rebel and only comply while being watched. However, the same person might willingly perform the same act if she is given information and the opportunity to exercise her agency in the decision.

Thus, while the relationship between intrinsic and extrinsic motivation is traditionally described as a dichotomy of "good" and "bad" motivation, SDT describes a spectrum for extrinsic motivation. More externally regulated extrinsic motivation has been shown to reduce interest, value, and effort towards achievement and lead students to blame their environment for negative outcomes. It may also engender anxiety and poor coping strategies for failure. In contrast, more autonomous and integrated extrinsic motivation is associated with more interest and enjoyment in school, positive coping styles, increased effort, more engagement, better performance, lower dropout rates, higher quality learning, and better teacher ratings [43]. In the context of gamification then, care should be taken to pair external motivators with the internal interests and informational needs of the learner, and arbitrary external rewards as a means to influence the learner should be avoided.

\subsection{SDT's Implications for Educational Gamification}

Some approaches to gamification emphasize externally regulated extrinsic motivators. These approaches are sometimes called "pointification" [41] or "exploitationware" [4], underscoring the feelings of mistrust and manipulation they can engender [3]. Care must be taken when employing an educational gamification approach to avoid externally regulated extrinsic motivators and promote intrinsic and autonomous extrinsic motivation. Motivational affordances theory offers suggestions for doing this.

\subsection{Motivational Affordances Theory}

Motivational affordances theory suggests that the properties of an element determine whether and how it can support the motivational needs of the learner. A number of motivational affordances have been described in the literature $[33,47,43,49,39,42,40$, 24]. The following list summarizes many of them, loosely organized by the three core principles of SDT: 2.7.1 Autonomy.

- Support autonomy

- Promote creation and representation of selfidentity and allow students to try on new identities and roles

- Align activities and goals with students' personal values and ensure they want to achieve them

- Allow students to define, create, modify, and share the game, content, and its rules

- Provide students with flexibility over movement, pace, goals undertaken, strategy, and the sequence of activities and tasks

- Avoiding unrelated external rewards or punishments as a means to promote motivation or control behavior; only use rewards as informational feedback

- Add elements of fun and play

\subsubsection{Competence.}

- Provide opportunities to acquire and acknowledge new knowledge, skills, and/or abilities

- Enable active experimentation and discovery

- Design for optimal challenge

- Provide guidance through a mastery process 
- Praise and reward practice, effort, strategy, process, focus, improvement, and perseverance as well as mastery

- Provide a variety of ways to demonstrate mastery

- Use a variety of methods to present content

- Provide timely and positive feedback

- Reward problem-solving with harder problems

- Make progress transparent to the user, provide progress indicators for each learning goal

- Provide for positive emotional experiences (e.g., curiosity, joy, optimism, pride)

- Help students persist through negative emotional experiences (e.g., frustration, failure, anxiety, fear, helplessness, overwhelmed)

- Help students convert negative emotional experiences into positive ones with rapid feedback cycles and low stakes

- Make coursework's future utility clear and ensure activities are interesting

\subsubsection{Relatedness.}

- Facilitate human-human interaction

- Represent human social bonds

- Facilitate one's desire to influence others

- Facilitate one's desire to be influenced by others

- Add peer voting to activities like online discussions and forums

- Encourage students to think of themselves differently as learners by publically taking on the role or identity of scholars and learners in the context of their peers

- Provide social credibility and recognition for academic achievements that might otherwise be invisible or denigrated by peers

- Explicitly train students how to adopt a growth vs. fixed mindset. Praise and reward practice, effort, strategy, process, focus, improvement, and perseverance as well as mastery.

Deterding [15] extended Motivational Affordances Theory by suggesting that the situation provides its own motivationally salient features and shapes game elements' motivational affordances. Transferring a game element from one environment (e.g., play) to another (e.g., a gamified course) does not necessarily mean it will have the same motivational affordances. Thus, game elements must be evaluated in specific contexts to understand their motivational power in that context. Identifying game elements that work well in educational gamification was a primary aim of this study.

\subsection{Game Elements: Dynamics, Mechanics, and Components}

Werbach and Hunter [48] present a useful structure for classifying game elements in gamification. Their model includes game dynamics, game mechanics, and game components. While a complete list is beyond the scope of this document, the following is a brief list of game elements compiled from the literature $[4,15]$ :

- Narrative context

- Feedback

- Advancing in levels

- Personal profiles and avatars

- Top scores and leaderboards

- Points for doing assignments

- Bonuses for exceeding expectations or extra difficult activities

- Messages, notifications, activity feeds, news, and updates

- Clear indications of next steps and what to expect

- Rank, status, and reputation

- Limited resources

- Market places and economies, virtual goods from points or badges

- Information on progression, e.g., progress bars

- Social activity, teams, groups, recognition from peers, peer pressure, peer comparison

- Deadlines, appointments, and curfews to drive activity

- Badges and achievements for activities outside of core course activities like helping peers, commenting, etc.

- Explicit and enforced rules

Chou [7] catalogs many more game elements and suggests that they can be categorized by those supporting each of the following nine core drives for human behavior: epic meaning and calling; development and accomplishment; empowerment of creativity and feedback; ownership and possession; social influence and relatedness; scarcity and impatience; unpredictability and curiosity; loss and avoidance; and sensation. Importantly, Deterding [15] notes that little granular research has been done on the motivational pull of specific game elements. These game elements need to be evaluated in the context of each other and in a course to identify their impact on motivation, engagement, and performance. The exploration of these relationships was a primary goal of this study.

\section{Research on Educational Gamification}

At this point, few studies have been conducted on 
the effects of gamification in education. Hamari et al. [23] conducted a broad meta-analysis on the effectiveness of gamified projects that includes nine studies related to education and learning. One hundred percent of the studies examined showed that at least some of the intended goals of gamification were achieved, though the majority of the studies also included some failed and/or inconclusive results. Cronk [10] found that a sense of fun, friendly competition, and status or peer recognition of achievement are motivators and that performance indicators can increase in-class participation. deMarcos, Domínguez, Saenz-de-Navarrete, and Pagés [14] found that a social networking course design resulted in better course outcomes than a gamified course design, but both outperformed a control group. Abrams and Walsh [2] found that a gamified environment led to more engagement and excitement for students in vocabulary exercises. Goehle found that the large majority of students in a gamified course tracked achievements and purposefully worked to achieve them. Students in that study reported that achievements provide positive reinforcement for completing assignments and a sense of progress. Also, those students preferred achievements that acknowledged effort [22]. Drace found that gamification helped Microbiology students feel engaged and interested [21] and Nevin et al found that it was well accepted by graduate medical students [38'].

Lambert and Ennis [31] found that when given the freedom to govern their own pace in a course, some students will finish early and some do more assignments than are required for an A. However, other students did not find gamification motivating. He suggests that scaffolding strategies should be used to aid students with low self-motivation. Lin (2014) found that gamification added objectivity to assessment and positively influenced the atmosphere in foreign language classrooms. Interaction with the language increased during class, students gave more effort, and the quality of communication improved. Students had greater excitement and engagement and a positive affect towards the class - they had fun [35]. Domínguez, Saenz-de-Navarrete [20] found that gamification e-learning platforms can have great emotional and social impact on capable students, improving motivation. However, gamification can be discouraging for students who do not compete well and increases in cognitive performance may be limited. Also, creating such a platform is not trivial and technical and usability issues can limit motivation.
Gamification's emphasis on engaging students at an emotional, social, and cognitive level has the potential to ameliorate some of online education's challenges described above. However, little research has been performed regarding educational gamification's impact on student motivation and performance and even less has been done on the influence of specific game elements. In this paper, we present our findings from gamifying an Organizational Behavior course. To advance our understanding and inform theory of how educational gamification fosters and influences learning in technology-rich environments, the following research question was investigated:

1. What are the underlying factors that govern which game elements are motivational to specific groups of students?

\section{Method}

\subsection{Design-based Research}

In this exploratory research we employ Designbased research (DBR), a research design method for systematically testing theoretical interventions in the messy context of learning environments [44, 5]. Its purpose is to ensure that resulting theory will have application in practice by "simultaneously and iteratively [addressing] the scientific processes of discovery, exploration, confirmation, and dissemination" [30]. Research questions and methods are grounded in rigorous theory, relevant literature, and practical experience. Researchers and designers begin with an innovation or theory and work together with participants in the real world in an iterative cycle of analysis, design, implementations, and redesign based on experience until the design is refined [9]. Cycles are driven by understanding what is not working well and taking steps to improve previous cycles. Analysis involves using a variety of qualitative and quantitative methods to gather rich data from the environment and users' experiences. In addition to a refined practical design, final outcomes for designbased research also include refined theoretical principles like an instructional design model and design rules. Theory resulting from DBR is evaluated by the extent to which it informs and improves practice.

\section{Research Question}


In keeping with DBR, we first created a gamification platform by skinning Canvas, the course LMS, to integrate multiple game elements (Figure 1). This innovation was grounded in the aforementioned literature on self-determination theory and gamification. In the following section, we describe our research with this initial platform and its results on student motivation.
- Bonus and penalty points for completing assignments before or after "best if done by" milestones

- Receiving points for assignments

- Being able to see course progress in the course map as assignments are completed

- Leaderboard showing current rank in class

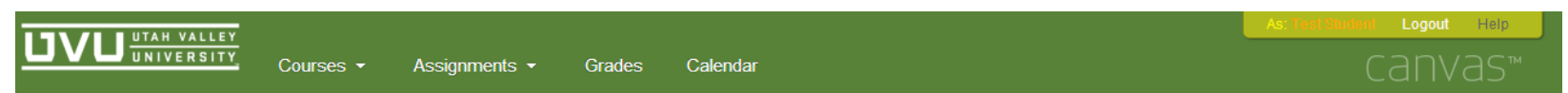

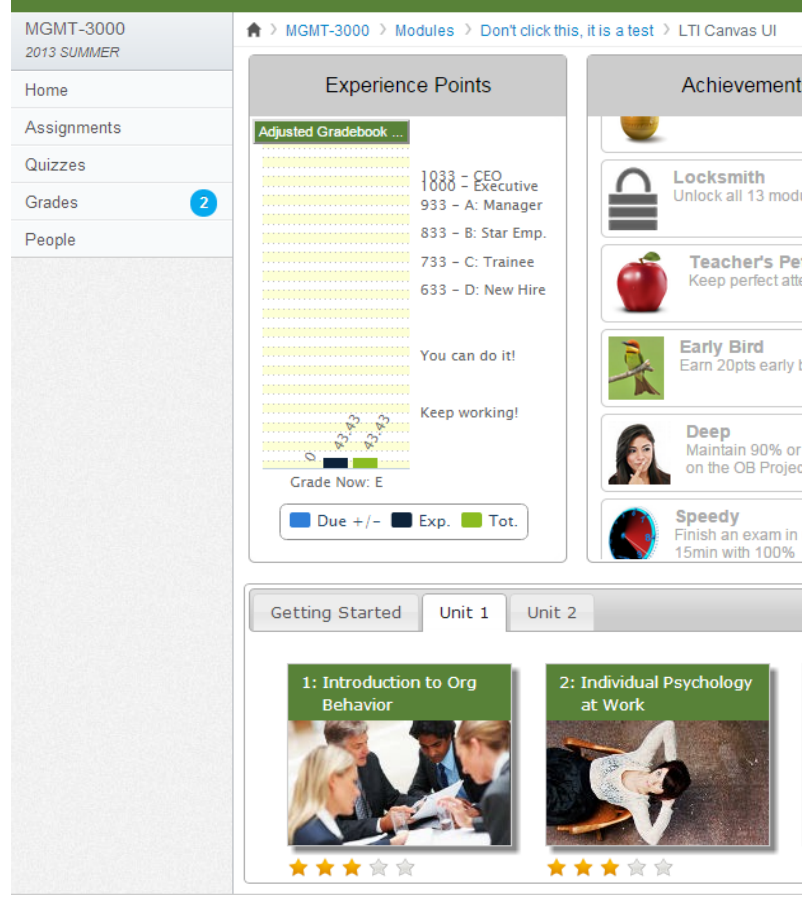

\subsection{Platform}

While teaching business courses, the first author pondered how students might "get addicted" to doing homework, similar to how some appeared to be addicted to smartphone games. He teaches at a local state university with open enrollment of about 33,000 students a year. He began designing a gamified course interface, drawing inspiration from games like Angry Birds and Plants vs. Zombies. In the summer of 2013, the first author created a gamified course skin and by Fall semester he had a pilot prototype ready. Using what he learned that semester, he refined his code and ran the pilot again in the Spring and Fall 2014 semesters (Figure 1). The platform was designed to include a broad range of game common elements so that we could evaluate which ones students found more motivating. The gamification platform included the following game elements:

- Freedom to do assignments at any time during the semester
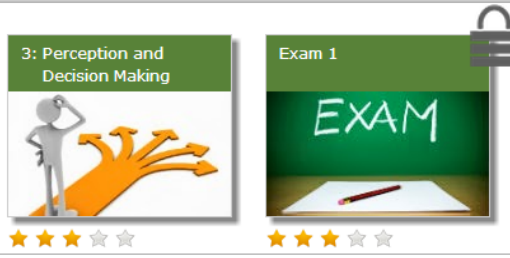

- Starting with 0 points in the class and advancing in levels by getting points as assignments are completed

- A bar chart indicating current points and grade in class

- Being able to complete exams indicating mastery in specific topics

- Being able to complete traditional course assignments

- Being able to unlock assignments by performing other assignments

- Achievements indicating completing specific tasks like maintaining 100\% attendance and scoring well on assignments

- Having multiple levels in the leaderboard (i.e., Gold, Diamond, Bronze, etc.) to work through

- Having student company aliases in the leaderboard so students can track the progress of specific peers in the class

- Reviewing peers' work and evaluating their performance 
- Having student work evaluated by their peers in a peer review assignment

\subsection{Measures}

A survey was developed to measure the perceived impact on motivation of each specific game element described above. It consisted of both Likert scale and open-ended questions. To measure the motivational impact of game elements, we asked:

Gamification includes a variety of game mechanics intended to influence your level of motivation. For EACH of the game mechanics listed BELOW, respond to the following statement: "In this course, due to this game mechanic, I was [Much Less, Less, Neither Less or More, More, Much More] motivated to do well than when compared to my typical level of motivation in other courses."

\subsection{Demographics}

184 students from 11 undergraduate Organizational Behavior courses responded to the survey during the 2013-2015 school years. Students who experienced the course during the first three semesters $(n=60)$ were asked by email to respond to the survey, and students during the last two semesters $(n=124)$ were asked to respond to the survey as an assignment in the course. All of the courses were taught by the same professor in the same format. $70.1 \%$ were male and $29.9 \%$ were female. Students ranged in age from 18 to over 41 years of age, with $79.9 \%$ being $20-30$ years old. The majority of students (78.3\%) were Caucasian, which is representative of the geographic demographics. The majority of students worked: $40.2 \%$ part-time and $33.7 \%$ full time. The majority of participants were full-time students $(87.0 \%)$ and $13.0 \%$ were part-time students.

We were surprised that, given the stereotype of a generation of video game players, nearly one-third of participants indicated that they play videogames of any kind less than once a month or never $(29.9 \%)$. $49.5 \%$ said that they played several times a week or daily and $20.7 \%$ said they played several times a month. We were also somewhat surprised to find that the distribution of participants' self-reported comfort level with technology was bimodal, with $14.7 \%$ indicating that they were very uncomfortable with technology, $1.1 \%$ indicating that they were uncomfortable, $19.6 \%$ indicating neutral and $64.7 \%$ indicating comfortable or very comfortable.

\section{RESULTS AND DISCUSSION}

We successfully piloted the gamification platform in eleven course sections over five semesters. We conducted a summative evaluation of the students' perceptions by sending out a post-course survey including the measures described above. Specifically, we investigated whether the students felt the gamified course was motivating overall and how motivating they felt each specific game element was.

\subsection{Descriptive}

We measured the level of motivation afforded by 16 game elements listed above; these scores are summarized in Table 1.

\begin{tabular}{|c|c|c|c|c|c|c|}
\hline $\begin{array}{l}\text { BLEE } 1 \\
\quad \text { Percent of Responses } G\end{array}$ & iven For & Each Mo & vation Leve & el for Each C & Game El & \\
\hline & $\begin{array}{l}\text { Average } \\
(1-5)\end{array}$ & $\begin{array}{l}\text { Much Less } \\
-1\end{array}$ & Less -2 & $\begin{array}{l}\text { Neither } \\
\text { less or } \\
\text { more -3 }\end{array}$ & More -4 & $\begin{array}{l}\text { Much } \\
\text { more }-5\end{array}$ \\
\hline Points for assignments & 4.1 & $1.60 \%$ & $2.20 \%$ & $17.40 \%$ & $46.70 \%$ & $32.10 \%$ \\
\hline Due date bonuses and penalties & 4 & $3.80 \%$ & $2.20 \%$ & $16.30 \%$ & $41.80 \%$ & $35.90 \%$ \\
\hline Due date flexibility & 4 & $3.30 \%$ & $4.90 \%$ & $20.10 \%$ & $34.20 \%$ & $37.50 \%$ \\
\hline Overall motivation & 3.9 & $3.30 \%$ & $3.30 \%$ & $21.20 \%$ & $44.00 \%$ & $28.30 \%$ \\
\hline Course map & 3.9 & $3.40 \%$ & $1.10 \%$ & $26.40 \%$ & $41.40 \%$ & $27.60 \%$ \\
\hline Doing assignments & 3.8 & $2.20 \%$ & $2.70 \%$ & $28.30 \%$ & $42.90 \%$ & $23.90 \%$ \\
\hline Current grade indicator & 3.7 & $5.40 \%$ & $5.40 \%$ & $24.50 \%$ & $39.10 \%$ & $25.50 \%$ \\
\hline Exams & 3.7 & $2.20 \%$ & $1.60 \%$ & $37.00 \%$ & $38.60 \%$ & $20.70 \%$ \\
\hline Leaderboard & 3.7 & $6.00 \%$ & $5.40 \%$ & $27.70 \%$ & $32.10 \%$ & $28.80 \%$ \\
\hline Unlocking assignments & 3.6 & $4.90 \%$ & $4.90 \%$ & $31.50 \%$ & $40.20 \%$ & $18.50 \%$ \\
\hline Starting with 0 points & 3.6 & $8.20 \%$ & $9.80 \%$ & $21.70 \%$ & $33.20 \%$ & $27.20 \%$ \\
\hline Leaderboard levels & 3.5 & $4.90 \%$ & $7.10 \%$ & $38.60 \%$ & $34.80 \%$ & $14.70 \%$ \\
\hline Aliases & 3.3 & $7.60 \%$ & $6.50 \%$ & $46.70 \%$ & $25.00 \%$ & $14.10 \%$ \\
\hline Doing peer reviews & 3.3 & $6.00 \%$ & $11.40 \%$ & $40.20 \%$ & $31.50 \%$ & $10.90 \%$ \\
\hline Achievements & 3.3 & $6.60 \%$ & $9.60 \%$ & $45.50 \%$ & $27.50 \%$ & $10.80 \%$ \\
\hline Receiving peer reviews & 3.2 & $10.30 \%$ & $10.90 \%$ & $40.80 \%$ & $28.30 \%$ & $9.80 \%$ \\
\hline
\end{tabular}

\subsection{Correlation}

Pearson's correlation coefficient was used to compute a correlation matrix for survey variables. Rows with missing data were dropped for specific correlation pairings and $\mathrm{p}$-values were computed for each correlation (see Table 2).

\subsection{Principle Components Analysis}

Finally, we conducted a Principal Component Analysis (PCA) to examine the underlying factor structure for game-element motivation (Table 3). The resulting bi-plots revealed three vectors arranged in an $\mathrm{x}-, \mathrm{y}-$, and $\mathrm{z}$-axis. The $\mathrm{z}$-axis is interpreted to indicate degree of motivation; this axis contained two planes. The first plane sat very near 0 and was comprised solely of all the demographic variables. This outcome indicates that no demographic characteristic was a predictor of motivation in a gamified course. All of the game elements sat in a second plane situated some distance away from 0 on the $\mathrm{z}$ or "motivation" axis. The other two vectors are shown in Figure 2. The farther a game element is from the origin, the more of 
Table 2

\begin{tabular}{|c|c|c|c|c|c|c|c|c|c|c|c|c|c|c|c|c|}
\hline Variable & Mean & s.d. & 2. & 3. & 4. & 5. & 6. & 7. & 8. & 9. & 10. & 11. & 12. & 13. & 14. & 15. 16 \\
\hline 1. BarChart & 3.74 & 1.07 & & & & & & & & & & & & & & \\
\hline 2. FreedomTime & 3.98 & $1.030 .43^{++}$ & & & & & & & & & & & & & & \\
\hline 3. Bonus & 4.04 & $0.980 .39^{++}$ & $+0.49^{++}$ & & & & & & & & & & & & & \\
\hline 4. Leaderboard & 3.72 & $1.120 .54^{++}$ & $+0.37^{++}$ & $0.39^{++}$ & & & & & & & & & & & & \\
\hline 5. Alias & 3.32 & $1.040 .35^{++}$ & $+0.28^{++}$ & $0.29^{++}$ & $0.54^{++}$ & & & & & & & & & & & \\
\hline 6. Levels & 3.47 & $0.990 .44^{++}$ & $+0.2^{++}$ & $0.33^{++}$ & $0.68^{++}$ & $0.59^{++}$ & & & & & & & & & & \\
\hline 7. Achievements & 3.26 & $1.000 .27^{++}$ & 0.12 & $20.23^{++}$ & $0.35^{++}$ & $0.36^{++}$ & $0.42^{++}$ & & & & & & & & & \\
\hline 8. Points & 4.05 & $0.850 .42^{++}$ & $+0.36^{++}$ & $0.43^{++}$ & $0.38^{++}$ & $0.31^{++}$ & $0.36^{++}$ & 0.11 & & & & & & & & \\
\hline 9. Start0 & 3.61 & $1.210 .41^{++}$ & ${ }^{+} 0.31^{++}$ & $0.33^{++}$ & $0.38^{++}$ & 0.12 & $20.21^{++}$ & $0.24^{++}$ & $0.42^{++}$ & & & & & & & \\
\hline 10. Assignments & 3.84 & $0.900 .35^{++}$ & $+0.5^{++}$ & $0.38^{++}$ & $0.3^{++}$ & $0.34^{++}$ & $0.27^{++}$ & $0.22^{++}$ & $0.58^{++}$ & $0.27^{++}$ & & & & & & \\
\hline 11. Exams & 3.74 & $0.880 .37^{++}$ & $+0.44^{++}$ & $0.42^{++}$ & $0.38^{++}$ & $0.36^{++}$ & $0.31^{++}$ & $0.26^{++}$ & $0.47^{++}$ & $0.38^{++}$ & $0.66^{++}$ & & & & & \\
\hline 12. Map & 3.89 & $0.940 .38^{++}$ & $+0.42^{++}$ & $0.31^{++}$ & $0.39^{++}$ & $0.41^{++}$ & $0.41^{++}$ & $0.37^{++}$ & $0.52^{++}$ & $0.38^{++}$ & $0.54^{++}$ & $0.5^{++}$ & & & & \\
\hline 13. DoPeerReview & 3.30 & $1.01 \quad 0.13$ & $30.21^{++}$ & $0.2^{++}$ & $0.34^{++}$ & $0.29^{++}$ & $0.22^{++}$ & $0.21^{++}$ & $0.25^{++}$ & $0.3^{++}$ & $0.29^{++}$ & $0.35^{++}$ & $0.26^{++}$ & & & \\
\hline 14. GetPeerReview & 3.16 & $1.080 .2^{++}$ & $0.18^{+}$ & $0.23^{++}$ & $0.33^{++}$ & $0.32^{++}$ & $0.27^{++}$ & $0.22^{++}$ & $0.21^{++}$ & $0.22^{++}$ & $0.3^{++}$ & $0.34^{++}$ & $0.23^{++}$ & $0.65^{++}$ & & \\
\hline 15. Unlock & 3.63 & $1.000 .39^{++}$ & ${ }^{+} 0.32^{++}$ & $0.38^{++}$ & $0.39^{++}$ & $0.39^{++}$ & $0.33^{++}$ & $0.37^{++}$ & $0.29^{++}$ & $0.45^{++}$ & $0.44^{++}$ & $0.53^{++}$ & $0.5^{++}$ & $0.17^{+}$ & $0.21^{++}$ & \\
\hline 16. Overall & 3.91 & $0.960 .66^{++}$ & $+0.42^{++}$ & $0.48^{++}$ & $0.65^{++}$ & $0.39^{++}$ & $0.5^{+}$ & $0.34^{++}$ & $0.43^{++}$ & $0.53^{++}$ & $0.33^{++}$ & $0.49^{++}$ & $0.42^{++}$ & $0.35^{++}$ & $0.36^{++}$ & $0.48^{++}$ \\
\hline
\end{tabular}

its variability is explained by the two-factor model. By plotting each game element in this two vector space and examining their characteristics, we identified two motivational dimensions: individual vs. social motivators and evaluation vs. exposition motivators. Evaluation refers to receiving feedback on specific assignments, and exposition refers to illustrating feedback on one's overall progress.

\begin{tabular}{lrrr}
\hline \multirow{2}{*}{ Variables } & \multicolumn{3}{c}{ Factor Loadings } \\
\cline { 2 - 5 } & PC1 & PC2 & PC3 \\
\hline BarChart & 0.51 & 0.55 & -0.12 \\
FreedomTime & 0.7 & 0.12 & 0.03 \\
Bonus & 0.59 & 0.28 & 0.03 \\
Leaderboard & 0.31 & 0.76 & 0.16 \\
A1ias & 0.2 & 0.67 & 0.23 \\
Leve1s & 0.16 & 0.83 & 0.09 \\
Achievements & 0.09 & 0.62 & 0.14 \\
Points & 0.71 & 0.16 & 0.11 \\
Start0 & 0.56 & 0.23 & 0.1 \\
Assignments & 0.78 & 0.04 & 0.25 \\
Exams & 0.72 & 0.17 & 0.29 \\
Map & 0.63 & 0.33 & 0.13 \\
DoPeerReview & 0.19 & 0.16 & 0.87 \\
GetPeerReview & 0.15 & 0.22 & 0.84 \\
Un1ock & 0.56 & 0.39 & 0.02 \\
Overal1 & 0.51 & 0.6 & 0.14 \\
\hline SS 1oadings & 4.23 & 3.31 & 1.79 \\
Proportion Var & 0.26 & 0.21 & 0.11 \\
Cumulative Var & 0.26 & 0.47 & 0.58 \\
Proportion Explained & 0.45 & 0.35 & 0.19 \\
Cumulative Proportion & 0.45 & 0.81 & 1 \\
\hline
\end{tabular}

Table 3

Principle components analysis based on 16 game element variables $(\mathbf{n = 1 8 4})$

The resulting two-factor space yields four quadrants, a $2 \times 2$ matrix, which models four styles of participant motivation (see Figure 2). Again, by evaluating the characteristics of game elements found in each quadrant, the quadrants and their accompanying motivation style have been labeled as follows: (1) Personal Progress - being motivated by gamified elements that show one's individual progress in a course; (2) Competition and Praise - being motivated by game elements that show one's progress compared to their peers and provide social reinforcing feedback; (3) Individual Assignments - being motivated by completing traditional assignments and exams; and (4) Group Work - being motivated by social assignments like group work and peer review.

The distribution of each participant (shown as points in Figure 2) plotted in this same two-factor space reveals that a variety of motivational styles were present in our sample, though individual motivation was favored. This suggests that there is no "silver bullet" for designing a gamified course that will motivate all students. Although a majority of students reported that the gamified interface was motivating, no single element, or combination thereof, seems to have been responsible for motivating everyone. Care should be taken to design courses to accommodate students from all four motivational styles by providing a variety of activities. While this factor space will obviously change as more game elements and populations are evaluated, it begins to form a framework for describing how game elements motivate students in educational gamification. We propose this framework with the hope that it will be refined by future research.

In addition, the individual vs. social vector found in this model has obvious similarities to introvert vs extrovert personalities. Codish and Ravid [8] also found differences in how these personality types experienced playfulness given a similar set of game elements.

While educational gamification is not a game it is 
interesting to compare the motivation styles for educational gamification found in this study to those identified in a meta-synthesis of player types performed by Hamari and Tuunane [50]. The characteristics of motivational styles could align with player types in the following ways: Personal Progress and Achievement; Group Work and Sociability; Competition and Praise and Domination. It is also interesting to observe that the Individual Assignments does not appear to have a direct correlation to a player type, suggesting that students with this motivation style simply don't want to play a game, they simply want to earn points and complete a class.

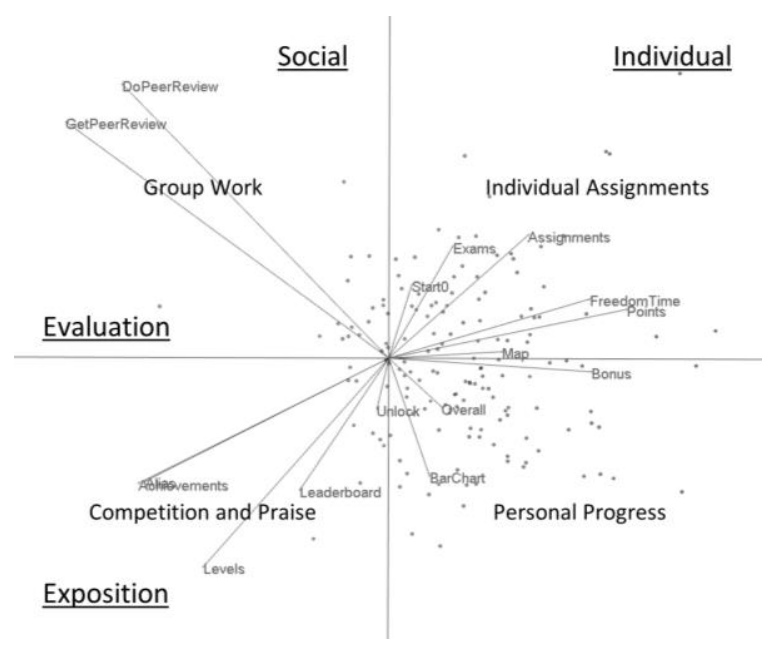

Figure 2

PCA Bi-Plot of the Underlying Factor Structure of Game Elements Revealing Two Vectors and Four Motivation Profiles

\section{References}

1. Anderson, J.Q. and L. Rainie, Gamification: Experts expect 'game layers' to expand in the future, with positive and negative results. Pew Research Center's Internet \& American Life Project, 2012.

2. Abrams, S.S. and S. Walsh, Gamified Vocabulary. Journal of Adolescent \& Adult Literacy, 2014.

3. Atchley, T.W., G. Wingenbach, and C. Akers, Comparison of course completion and student performance through online and traditional courses. The International Review of Research in Open and Distance Learning, 2013. 14(4).

4. Bogost, I., Persuasive games: exploitationware. Retrieved January, 2011. 9: p. 2013.

5. Brown, A.L., Design experiments: Theoretical and methodological challenges in creating complex interventions in classroom settings. Journal of the Learning Sciences, 1992: p. 141-178.

6. Bunchball. (2010). Gamification 101: An Introduction to the Use of Game Dynamics to Influence Behavior.

7. Chou, Y.-K., Actionable Gamification: Beyond Points,
Badges, and Leaderboards. 2015.

8. Codish, D., \& Ravid, G. (2014). Personality based gamification-Educational gamification for extroverts and introverts. In Proc. 9 th Chais Conf. for the Study of Innovation and Learning Technologies: Learning in the Technological Era.

9. Collins, A., D. Joseph, and K. Bielaczyc, Design research: Theoretical and methodological issues. The Journal of the learning sciences, 2004. 13(1): p. 15-42.

10. Cronk, M., Using Gamification to Increase Student Engagement and Participation in Class Discussion, in World Conference on Educational Multimedia, Hypermedia and Telecommunications 2012, T. Amiel and B. Wilson, Editors. 2012, AACE: Denver, Colorado, USA. p. 311-315.

11. Deci, E.L. and R. Ryan, Overview of self-determination theory: An organismic dialectical perspective. Handbook of self-determination research, 2002: p. 333.

12. Deci, E.L., R. Koestner, and R.M. Ryan, A metaanalytic review of experiments examining the effects of extrinsic rewards on intrinsic motivation. Psychological bulletin, 1999. 125(6): p. 627.

13. Deci, E.L., R. Koestner, and R.M. Ryan, Extrinsic rewards and intrinsic motivation in education: Reconsidered once again. Review of educational research, 2001. 71(1): p. 1-27.

14. de-Marcos, L., et al., An empirical study comparing gamification and social networking on e-learning. Computers \& Education, 2014. 75: p. 82-91.

15. Deterding, S. Situated motivational affordances of game elements: A conceptual model. in Gamification: Using Game Design Elements in Non-Gaming Contexts, a workshop at CHI. 2011.

16. Deterding, S. (2011). Situated motivational affordances of game elements: A conceptual model. Paper presented at the Gamification: Using Game Design Elements in Non-Gaming Contexts, a workshop at CHI.

17. Deterding, S., Dixon, D., Khaled, R., \& Nacke, L. (2011). From game design elements to gamefulness: Defining "gamification". Paper presented at the Proceedings of the 15th International Academic MindTrek Conference: Envisioning Future Media Environments, Tampere, Finland. http://dl.acm.org/citation.cfm?id=2181037.2181040

18. Deterding, S., Dixon, D., Khaled, R., \& Nacke, L. (2011). Gamification: Toward a Definition. http://gamification-research.org/wpcontent/uploads/2011/04/02-Deterding-Khaled-NackeDixon.pdf

19. Deterding, S., Sicart, M., Nacke, L., O'Hara, K., \& Dixon, D. (2011). Gamification: Using game-design elements in non-gaming contexts. Paper presented at the CHI'11 Extended Abstracts on Human Factors in Computing Systems.

20. Domínguez, A., et al., Gamifying learning experiences: Practical implications and outcomes. Computers \& Education, 2013. 63(0): p. 380-392.

21. Drace, K., Gamification of the Laboratory Experience to Encourage Student Engagement. Journal of Microbiology \& Biology Education : JMBE, 2013. 
14(2): p. 273-274.

22. Goehle, G., Gamification and Web-based Homework. PRIMUS, 2013. 23(3): p. 234-246.

23. Hamari, J., J. Koivisto, and H. Sarsa. Does Gamification Work?--A Literature Review of Empirical Studies on Gamification. in System Sciences (HICSS), 2014 47th Hawaii International Conference on. 2014. IEEE.

50. Hamari, J., \& Tuunanen, J. (2014). Player types: A meta-synthesis. Transactions of the Digital Games Research Association, 1(2), 29-53.

24. Heeter, C., et al., Impacts of forced serious game play on vulnerable subgroups. International Journal of Gaming and Computer-Mediated Simulations (IJGCMS), 2011. 3(3): p. 34-53.

25. Huang, W.H.-Y. and D. Soman, A Practitioner's Guide To Gamification Of Education. 2013, Rotman School of Management University of Toronto.

26. Huotari, K., \& Hamari, J. (2012). Defining gamification: a service marketing perspective. Paper presented at the Proceeding of the 16th International Academic MindTrek Conference.

27. Jaggars, S.S., Online Learning: Does It Help LowIncome and Underprepared Students? CCRC Working Paper No. 26. Assessment of Evidence Series. Community College Research Center, Columbia University, 2011.

28. Johnson, L., et al., The NMC horizon report: 2013 higher education edition. 2013.

29. Kapp, K. M. (2012). The gamification of learning and instruction: game-based methods and strategies for training and education: John Wiley \& Sons.

30. Kelly, A., Theme issue: The role of design in educational research. Educational Researcher, 2003. 32(1): p. 3-4.

31. Lambert, J. and J. Ennis. Quest-Based Learning: A New Approach to Preservice Teacher Technology Instruction. in Society for Information Technology \& Teacher Education International Conference. 2014.

32. Landers, R. N. (2015). Developing a theory of gamified learning: Linking serious games and gamification of learning. Simulation \& Gaming, 45,752-768.

33. Lee, J.J. and J. Hammer, Gamification in Education: What, How, Why Bother? Academic Exchange Quarterly, 2011. 15(2).

34. Liaw, S.-S., Investigating students' perceived satisfaction, behavioral intention, and effectiveness of e-learning: A case study of the Blackboard system. Computers \& Education, 2008. 51(2): p. 864-873.

35. Lin, N. Assessing Classroom Participation and Performance through Gamification Systems in Foreign Language Classrooms. in Society for Information Technology \& Teacher Education International Conference. 2014.

36. McGonigal, J., Reality Is Broken: Why Games Make Us Better and How They Can Change the World. 2011: Penguin Group, The. 400.

37. Muntean, C.I., Raising engagement in e-learning through gamification. The 6th International Conference on Virtual Learning, 2011.

38. Nevin, C.R., et al., Gamification as a tool for enhancing graduate medical education. Postgrad Med J, 2014. 90(1070): p. 685-93.

39. Nicholson, S., A user-centered theoretical framework for meaningful gamification. Games+ Learning+ Society, 2012. 8: p. 1.

40. Norman, D.A., The design of everyday things. 2002: Basic books.

41. Robertson, M., Can't play, won't play. Hide and seek: Inventing new kinds of play. 2010.

42. Rose, D.H. and A. Meyer, Teaching every student in the digital age: Universal design for learning. 2002: ERIC.

43. Ryan, R.M. and E.L. Deci, Self-determination theory and the facilitation of intrinsic motivation, social development, and well-being. American psychologist, 2000. 55(1): p. 68.

44. Shavelson, R.J., et al., On the science of education design studies. Educational Researcher, 2003. 32(1): p. 25-28.

45. Sheldon, L. (2012). The multiplayer classroom: Designing coursework as a game: Cengage Learning.

46. Simões, J., R.D. Redondo, and A.F. Vilas, A social gamification framework for a K-6 learning platform. Computers in Human Behavior, 2013. 29(2): p. 345353.

47. Smith-Robbins, S. "This Game Sucks": How to Improve the Gamification of Education. 2011; Available from: http://www.educause.edu/ero/article/game-sucks-howimprove-gamification-education.

48. Werbach, K. and D. Hunter, For the win: How game thinking can revolutionize your business. 2012: Wharton Digital Press.

49. Zhang, P., Technical opinion Motivational affordances: reasons for ICT design and use. Communications of the ACM, 2008. 51(11): p. 145147. 